\title{
MULTIPLE INCLUSIONS IN DIAMONDS: EVIDENCE FOR COMPLEX PETROGENESIS
}

\author{
Taylor, Lawrence A. ${ }^{1}$, Bulanova, Galina P. ${ }^{2}$, Snyder, Gregory A. ${ }^{1}$, Keller, Randall A. \\ 1 Planetary Geosciences Institute, University of Tennessee, Knoxville, TN 37996; lataylor@utk.edu \\ 2 TsNIGRI, 129B, Varshavsky shosse, Moscow, Russia; galina_bulanova@hotmail.com
}

"Diamonds are accidental inclusions in kimberlite and thus are xenocrysts; the association of diamond and kimberlite being one of passenger and transporting vehicle." H.O.A. Meyer (1985)

The concept that diamonds originated in peridotites and eclogites, and not in the kimberlites where they often occur, appeared to simplify the quest for understanding the formation of diamond. Further simplifying this quest was the idea that diamonds are phenocrysts as part of the igneous assemblage of their host rocks, the peridotites and eclogites. However, evidence has been mounting for mantle metasomatism as an additional controlling process in diamond formation. Collectively, it is evident that mantle metasomatism, metamorphism, partial melting, and kimberlite metasomatism may have significantly altered diamonds and their host xenoliths; the primary mineral chemistry of the host xenoliths can be virtually obliterated. But the pristine inclusions in diamonds may hold the critical answers about the formation and evolution of diamond.

Mineral inclusions in diamonds, the "time capsules" of Bulanova (1995), are effectively isolated from later mantle differentiation and/or metasomatism. These inclusions are snap-shots of their hosts and can provide evidence of the chemical environment at the time of their encapsulation by the growing diamond. Supporting an igneous origin for diamond is the observation that the compositions of many diamond inclusions (DIs) are similar to those same minerals in the host eclogites (Ireland et al., 1994; Taylor et al., 1996). However, there are commonly minor differences in chemistry as a result of metasomatism and/or partial melting of eclogites. As detailed in Table 1, $\mathrm{Na}_{2} \mathrm{O}$ in $\mathrm{Gt}$ and $\mathrm{K}_{2} \mathrm{O}$ in $\mathrm{Cpx}$ are slightly higher in the DI than in the host eclogite; $\mathrm{MgO}$ is higher and $\mathrm{FeO}$ is lower in the host $\mathrm{Gt} \& \mathrm{Cpx}$. $\mathrm{Na}_{2} \mathrm{O}$ is higher in the host $\mathrm{Cpx}$. Inasmuch as $\mathrm{K}$ in diamond appears to be a function of $\mathrm{P}$ (Harlow \& Veblen, 1991), the core to rim decrease in $\mathrm{K}_{2} \mathrm{O}$ may reflect a decrease in $\mathrm{P}$ during diamond growth. Furthermore, multiple DIs of Gt and Cpx commonly have identical major and trace element contents supporting rapid, uninterrupted growth-mode for diamond.

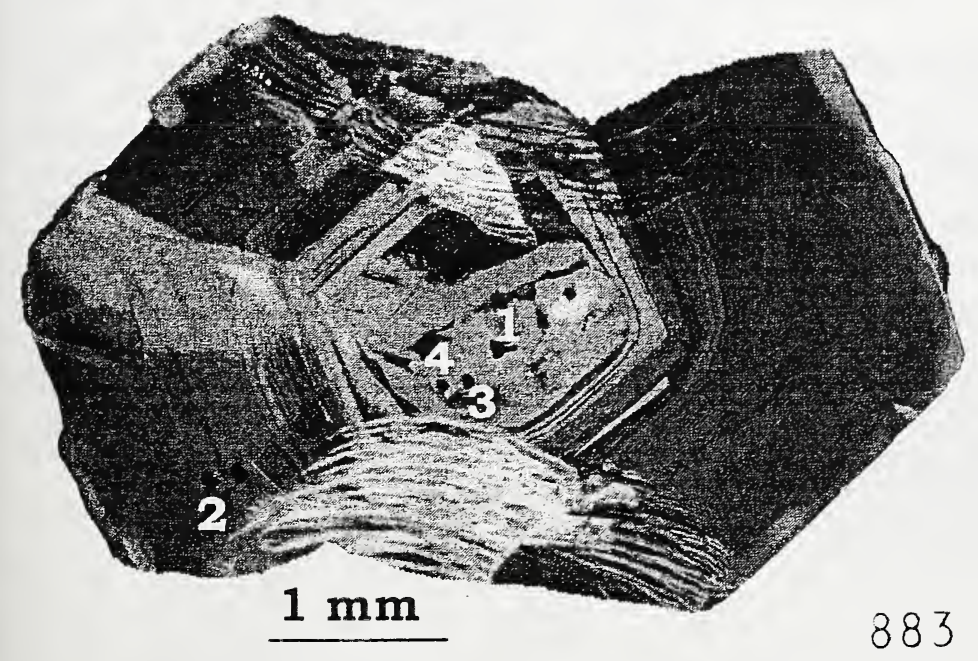

FIG. 1. CL Image of Diamond Mir-1572 displaying 3 main growth zones. CENTRAL ZONE has octahedral shape and yellow CL color; it is inhomogeneous internally, but has few growth layers towards the margin. INTERMEDIATE ZONE, with blue color, consists of fine growth layers of octahedral shape; in the early part of this Zone, growth oscillated with periods of resorption at the corners. The RIM ZONE is wide and homogeneous with dark-blue CL color. The Cpx grains are numbered, corresponding to analyses in Table 2. 
TABLE 1. Cpx Chemistry of DIs \& Host Eclogites

\begin{tabular}{|c|c|c|}
\hline & $\frac{\text { DIs Mir-1572 }}{\text { [This study] }}$ & $\frac{\text { DI / Host }}{\text { [Taylor et al., 1996] }}$ \\
\hline & $\Delta:$ Core to $\operatorname{Rim}(\%)$ & $\triangle: D I$ to Host M-46 (\%) \\
\hline $\mathrm{MgO}$ & \begin{tabular}{l|l} 
Increase & $8.65-10.7$
\end{tabular} & Increase \\
\hline $\mathrm{FeO}$ & Decrease & Decrease \\
\hline $\mathrm{Na}_{2} \mathrm{O}$ & Increase & Increase \\
\hline $\mathrm{K}_{2} \mathrm{O}$ & Decrease $0.20-0.13$ & Decrease \\
\hline $\mathrm{TiO}_{2}$ & Increase $\quad 0.2-0.5$ & $0.46-0.52$ \\
\hline
\end{tabular}

In contrast, there is an increasing body of data indicating notable differences among multiple DIs from the same diamond (e.g., Bulanova et al., 1986, 1995; Griffin et al, 1993; Sobolev et al., 1996). In fact, compositions of multiple DIs can differ so markedly that they may indicate mixed inclusion paragenesis (peridotite + eclogite) within a single diamond (e.g., Prinz et al., 1975). Rudnick et al. (1992) determined substantial differences in $\mathrm{Pb}$ isotopes in sulfides from three growth zones in a diamond and proposed drastic changes between each stage, an interpretation subsequently simplified by Bulanova et al. (1996), based upon a detailed trace-element study. Basically, diamonds with simple internal structures, represented by the 'stratigraphy' of Harrison and Tolansky (1964), which are consistent with continuous single-stage growth, show little variation in DI chemistry, whereas those with complex growth and resorption zonations contain DIs with a relatively wide range in trace-element composition. This statement is the result of detailed sulfide, oxide, and silicate DI trace-element studies (Bulanova, 1995; Bulanova et al., 1996). It appears that DI chemistry and diamond stratigraphy represent changes in the chemical environment as crystallization of the diamond progressed, and resulted in the observed discontinuous growth and chemical variations.

RESULTS: In a further attempt to investigate the environment for diamond formation and growth, we have examined $\mathrm{Cpx}$ and Gt inclusions in Type $\mathrm{E}$ diamonds from the Mir kimberlite. Their majorelement chemistry is presented in Table 2. Mir diamond 1572 has a complex zonation (Fig. 1) with multiple inclusions of $\mathrm{Cpx}$. The three $\mathrm{Cpx}$ grains in the core $(\# 1,3,4)$ have identical chemistry, whereas the Cpx from the rim (\#2) has a distinctly different composition, similar to the results of Bulanova (1995).

TABLE 2. Inclusion Chemistry from Mir Diamonds

\begin{tabular}{|c|c|c|c|c|c|c|}
\hline & \multicolumn{5}{|c|}{ Mir-1572 Cpx } & \multicolumn{2}{c|}{ Mir-1168 Cpx } \\
\hline & 1 Core & 3 Core & 4 Core & 2 Rim & 1 Rim & 2 Rim \\
\hline $\mathrm{SiO}_{2}$ & $55.1(2)$ & $54.8(1)$ & $54.9(1)$ & $55.1(1)$ & $54.9(1)$ & $55.0(1)$ \\
\hline $\mathrm{TiO}_{2}$ & $0.21(3)$ & $0.20(1)$ & $0.23(1)$ & $0.52(3)$ & $0.67(1)$ & $0.65(3)$ \\
\hline $\mathrm{Al}_{2} \mathrm{O}_{3}$ & $11.1(1)$ & $11.1(1)$ & $11.0(1)$ & $8.56(5)$ & $8.97(6)$ & $9.04(4)$ \\
\hline $\mathrm{Cr}_{2} \mathrm{O}_{3}$ & $0.10(1)$ & $0.12(1)$ & $0.10(1)$ & $0.09(3)$ & $0.09(2)$ & $0.08(2)$ \\
\hline $\mathrm{MgO}$ & $8.67(2)$ & $8.70(1)$ & $8.62(5)$ & $10.7(1)$ & $0.09(2)$ & $9.95(4)$ \\
\hline $\mathrm{CaO}$ & $12.9(3)$ & $12.9(1)$ & $12.8(1)$ & $13.2(1)$ & $12.8(1)$ & $12.8(1)$ \\
\hline $\mathrm{MnO}$ & $0.06(2)$ & $0.05(1)$ & $0.12(2)$ & $0.06(2)$ & $0.07(2)$ & $0.07(1)$ \\
\hline $\mathrm{FeO}$ & $5.33(9)$ & $5.26(3)$ & $5.36(2)$ & $5.14(5)$ & $5.76(2)$ & $5.68(1)$ \\
\hline $\mathrm{Na}_{2} \mathrm{O}$ & $5.34(3)$ & $5.29(7)$ & $5.29(6)$ & $5.59(8)$ & $5.72(8)$ & $5.79(1)$ \\
\hline $\mathrm{K}_{2} \mathrm{O}$ & $0.23(1)$ & $0.20(1)$ & $0.18(1)$ & $0.13(1)$ & $0.18(1)$ & $0.17(1)$ \\
\hline Total & 99.0 & 98.7 & 98.9 & 99.1 & 99.2 & 99.2 \\
\hline
\end{tabular}

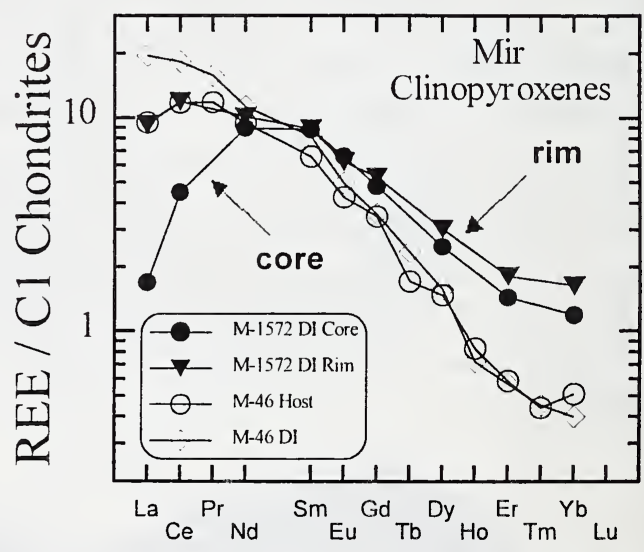

FIGURE 2. REE Contents of Diamond Inclusions and an Eclogite Host. Note that metasomatism of the M-1572 Core DI could result in the LREE enrichment shown by $M$ 1572 Rim DI. In contrast, partial melting of the very LREE-rich M-46 DI could result in the M46 Host pattern. That is, for these Mir samples, there is a commonality of the late-stage compositions. M-46 DI and Host data from Taylor et al. (1996). 
When the core-Cpx chemistry is compared to that in the rim-Cpx, some interesting differences are obvious, as noted in Table 1. These chemical changes from the core-to the rim-Cpxs are in the same direction and similar in magnitude to the changes observed in Cpx DIs versus their host eclogites (Table 1), as reported by Taylor et al. (1996). The agreement in trends shows that these changes of chemistry took place during continuous growth of the diamond, and that eclogitic diamonds in kimberlites are xenocrysts derived from diamondiferous eclogites.

With the Mir 1572 DIs (Fig.2), the rim-Cpx, with its enriched LREEs, represents an environment which has been significantly metasomatized versus that for the core-Cpxs. Although the majorelement chemistry of the DI Cpx versus the host Cpx of M-46 (Table 1) is in the exact same direction as that for core- versus rim-Cpx DIs in Mir 1572, the REE patterns (Fig. 2) show that the host Cpx would appear to have been partially melted relative to the DI. It would appear that the late-stage DI in Mir 1572 and the host of M-46 have come to a common chemistry, both situations representing the later stages of diamond-growth environment. It is probable that the Mir 1572 diamond experienced discontinuous growth over an extended period of time, perhaps over many millions of years. This evolution of compositions of the Cpx DIs from core to rim is contrary to that expected from igneous crystallization. Indeed, it is probable that later growth of the outer portions of the diamond formed after xenolith crystallization and involved $C$-and $N$-bearing fluids, such as those suggested by Deines and Harris (1994) and Stachel and Harris (1997).

Beard, B.L., K.N. Fraracci, L.A. Taylor, G.A. Snyder, R.N. Clayton, T.K. Mayeda, \& N.V. Sobolev, 1996, Petrography and geochemistry of eclogites from Mir kimberlite, Russia. Contrib. Mineral. Petrol. 125, 293-310.

Bulanova, G.P., 1995, The formation of diamond. Jour. Geochem. Explor. 53, 1-23.

Bulanova, G.P., N.V. Leskova, and L.A. Pavlova, 1986, Zonal distribution and evolution of chemical composition of syngenetic inclusions in diamonds. In Physical Properties and Mineralogy of Natural Diamond, Yakutsk, 45-72.

Bulanova, G.P., W.L. Griffin, C.G. Ryan, O.Y. Shestakova, and S.-J. Barnes, 1996, Trace elements in sulfide inclusions from Yakutian diamonds. Contrib. Mineral. Petrol. 124, 111-125.

Deines, P., and J.W. Harris (1994) On the importance of fluids for diamond growth (abstract). Goldsclimidt Conf., Edinburgh, 219-220.

Griffin, W.L., N.V. Sobolev, C.G. Ryan, N.P. Pokhilenko, T.T. Win, and E.S. Yefimova, 1993, Trace elements in garnets and chromite diamond formation in the Siberian lithosphere. Lithos 29, 235-256.

Harlow, G.E., \& D.R. Veblen, 1991, Potassium in clinopyroxene inclusions from diamonds. Science 25I, 652-655.

Harrison, E.R., and S. Tolansky, 1964, Growth history of a natural octahedral diamond. Proc. Royal Soc. London, A279, 490-496.

Ireland, T.R., R.L. Rudnick, and Z. Spetsius, 1994, Trace elements in diamond inclusions from eclogites reveal link to Archean granites. Earth Planet. Sci. Lett. 128, 199-213.

Meyer, H.O.A., 1985, Genesis of diamond: A mantle saga. Amer. Mineral. 70, 344-355

Moore, R.O., and J.J. Gurney, 1989, Mineral inclusions in diamond from the Monastery kimberlite, South Africa. In Ross et al. (editors) Kimberlites and Related Rocks, Volume 2, Proc. $4^{\text {th }}$ Int'l Kimberlite Conf., 1029-1041.

Prinz, M., D.V. Manson, P.F. Hlava, and K. Keil, 1975, Inclusions in diamonds: Garnet therzolite and eclogite assemblages. Physics \& Chemistry of the Earth 9, 797-815.

Rudnick, R.L., C.S. Eldridge, and G.P. Bulanova, 1992, Diamond growth history from in situ measurements of $\mathrm{Pb}$ and $\mathrm{S}$ siotopic compositions of sulfide inclusions. Geology 2l, 13-16.

Sobolev, N.V., E.S. Yefimova, L.A. Taylor, G.A. Snyder, \& V.N. Sobolev, 1996, Major \& trace element variations in multiple eclogitic inclusions in individual diamonds from Yakutia, Russia. Trans. Amer. Geophys. Union, S-287.

Stachel, T., \& J.W. Harris, 1997, Diamond precipitation and mantle metasomatism - Evidence from the trace-element chemistry of silicate inclusions in diamonds from Akwatia. Contrib. Mineral. Petrol. 129, 143-154.

Taylor, L.A., G.A. Snyder, G.Crozaz, V.N. Sobolev, E.S. Yefimova, and N.V. Sobolev, 1996, Eclogitic inclusions in diamonds: Evidence of complex mantle processes over time. Earth Planet. Sci. Lett. 142, 535-551. 